\title{
Corrosion Inhibition and Adsorption Behavior of Extract of Funtumia elastica on Mild Steel in Acidic Solution
}

\author{
${ }^{*}$ Adindu Chinonso Blessing ${ }^{1,2 a}$, Oguzie Emeka Emmanuel ${ }^{2 b}$ \\ and Chidiebere Maduabuchi Arinzechukwu ${ }^{2 \mathrm{c}}$
}

\author{
${ }^{* 1}$ Department of Chemistry, Imo State University, P M B 2000, Owerri, Imo state, Nigeria. \\ ${ }^{2}$ Electrochemistry and Material Science Research Laboratory, Department of Chemistry, \\ Federal University of Technology, P M B 1526, Owerri, Imo state Nigeria. \\ *ablessingadindu73@gmail.com, boguziemeka@yahoo.com \\ and 'arinzechukwuchidiebere@gmail.com
}

\begin{abstract}
Keywords: corrosion inhibition, mild steel, Fourier Transformed Infrared Spectroscopy, Funtumia elastica, Density functional theory,
\end{abstract}

\begin{abstract}
The corrosion and adsorption behavior of leaf extract of Funtumia elastica (FE) on mild steel corrosion was studied in $1 \mathrm{M} \mathrm{HCl}$ using gravimetric ,electrochemical impedance spectroscopy, potentiodynamic polarization and Fourier transformed infrared spectroscopy methods, Quantum chemical calculations were performed to theoretically correlate the inhibition performance of the inhibitor with its electronic structural parameters. The gravimetric experiment revealed that the extract effectively inhibited the corrosion of mild steel even at a prolonged exposure time. The impedance and polarization results revealed that the extract inhibited both the cathodic and anodic partial reactions via the adsorption of the inhibitor on the metal/solution interface. The FTIR results revealed $\mathrm{FE}$ as an adsorption inhibitor. The calculated quantum chemical parameters associated with the molecular structure of FE confirmed its inhibiting efficacy.
\end{abstract}

\section{INTRODUCTION}

Mild steel has found applications in many industries, but excessive corrosion attack is known to affect this industrial raw material. The corrosion attack can be reduced to a very reasonable state by the use of corrosion inhibitors [1]. The high cost of most commercial corrosion inhibitors coupled with the recent environmental awareness has necessaeted the motivation into the use of natural materials as corrosion inhibitors [2-10]. These materials have proven to be less toxic, cheap, environmental friendly and readily available and yet as effective as most commercial inhibitors such as chromate compounds [11-15]. It has been reported severally that most materials of plant origin which are used as corrosion inhibitors are rich in heteroatoms containing oxygen, nitrogen and/or sulphur in a conjugated system [16-20]. These materials function by adsorption of the material on the surface of the metal creating a barrier between the metal and the aggressive corrodent [21].

Again it has been reported that these natural materials contain a number of phytochemicals (tannins, alkaloids carbohydrates steroids e.t.c) which have electronic and molecular structures closely related to conventional corrosion inhibitors and which have been found to inhibit metal corrosion [22]. Oguzie et al [23] reported that acid extract of Piper guineense effectively reduced the corrosion of mild steel in both hydrochloric and tetraoxosulphate (VI) acid media. Also Patel and co-workers [24] have investigated the corrosion inhibition of mild steel by leave extracts of Wrightiatinctoria, Clerodendrumphlomidis and Ipomoeatriloba and the study revealed that the plants inhibited the corrosion of mild steel in $0.5 \mathrm{M} \mathrm{H}_{2} \mathrm{SO}_{4}$.

With regard to our continuous interest in the use of raw materials of plant origin as corrosion inhibitors, we here in report the corrosion inhibition of mild steel in $1 \mathrm{M} \mathrm{HCl}$ by ethanol extract of the leaves of Funtumia elastic using both gravimetric and electrochemical methods. FTIR was used to ascertain the adsorption behavior and density functional theory (DFT) was used to determine the individual contribution of the extract constituents to the total adsorption process. 


\section{DETAILS OF EXPERIMENTAL PROCEDURE}

Material preparations: Tests were performed on mild steel with the following weight percentage composition: $\mathrm{C}-0.05 ; \mathrm{Mn}-0.6 ; \mathrm{P}-0.36 ; \mathrm{Si}-0.3$ and the balance Fe. The aggressive solution used was $1 \mathrm{M} \mathrm{HCl}$ prepared from analytical grade reagents. Stock solutions were prepared from the plant extract by refluxing weighed amount of the dried and ground plant material for $3 \mathrm{~h}$ in absolute ethanol. The resulting solution was cooled and triple filtered. The amount of plant material that was extracted into the absolute ethanol was quantified by comparing the weight of the dried residue with the weight of the dried material before extraction. Test solutions of concentration $(50,200,400$, $600,800,1000$ and $1500 \mathrm{mg} / \mathrm{L}$ ) were prepared from the stock solution by dilution.

Gravimetric experiments: The mild steel coupons used for the gravimetric experiment have the following dimension $3 \mathrm{~cm} \times 3 \mathrm{~cm} \times 0.14 \mathrm{~cm}$. The coupons were obtained from a commercial source and cut into the desired dimension. The coupons were wet polished with silicon carbide abrasive paper of grade 400\# to \#1000, rinsed in distilled water, dried in acetone and warm air, weighed and stored in moisture free desiccators for use when desired. Tests were performed on the prepared coupons by total immersion into the test solutions. The coupons were suspended in beakers containing $300 \mathrm{ml}$ of the solutions using hooks and rods. To determine the weight loss, the coupons were retrieved after $24 \mathrm{~h}$ intervals progressively for $120 \mathrm{~h}$, and left for another $216 \mathrm{~h}$ un-retrieved making a total of $336 \mathrm{~h}$. When retrieved the coupons were immersed in $20 \% \mathrm{NaOH}$ solution containing $200 \mathrm{~g} / \mathrm{L}$ of zinc dust, scrubbed with bristle brush, washed dried, reweighed and reimmersed into the test solutions. The weight loss was determined as a difference between the weight of the coupon at a given time and the initial weight of the coupon. All tests were performed in quardriplate and the data gave good reproducibility. Average values were obtained and used for subsequent calculations.

Electrochemical experiments: The electrochemical experiments were performed on mild steel coupons with the following dimension $1 \times 1 \mathrm{~cm}^{2}$. And was fixed in polytetrafluoroethylene (PTFE) rods by epoxy resin in such a way that only one surface of area $1 \mathrm{~cm}^{2}$ was exposed. The uncovered area was cleaned as described earlier in the gravimetric section. Electrochemical tests were conducted in a conventional three electrode glass cell of capacity $400 \mathrm{ml}$ using a VERSASTAT 400 complete DC Voltammetry and corrosion system with a V3 software. The counter electrode was a graphite rod while the reference electrode was a saturated calomel electrode. The reference electrode was connected via luggin's capillary. The test solution was left for $1 \mathrm{~h}$ in an aerated and unstirred condition at $30^{\circ} \mathrm{C}$. Impedance experiments were made at corrosion potentials $\left(\mathrm{E}_{\text {corr }}\right)$ over a frequency range of $100 \mathrm{kHz}-10 \mathrm{MHz}$ using a signal amplitude perturbation of $5 \mathrm{mV}$. Potentiodynamic polarization experiments were performed in the potential range of $\pm 250 \mathrm{mV}$ versus corrosion potential at $0.333 \mathrm{mV} / \mathrm{s}$ scan rate. Each experiment was performed in triplicate to ensure that the obtained results are reproducible.

Transformed Infrared Spectroscopy experiments: Fourier transformed infrared spectroscopy (KBr pellet) was recorded using a Nicolet Magma-IR 560 FTIR spectrophotometer. The spectra for FE powder before and after extraction were recorded. Also recorded was the spectra of the protective fumes scraped from the surface of the mild steel coupon after immersion in a solution containing $1500 \mathrm{mg} / \mathrm{L} \mathrm{FE}$ extract by carefully removing the fumes, mixing it with $\mathrm{KBr}$, and making the pellet.

Computational consideration: All computational calculations were done using the DFT electronic structure analysis programs VAMP and $\mathrm{DMol}^{3}$ as explained in the Material studio modeling 4.0 soft ware (accelrys. Inc.). 


\section{RESULTS AND DICUSSION}

Gravimetric results: Gravimetric experiments were undertaken to study the effect of time on the inhibitive effect of the ethanol extract of FE on mild steel corrosion. The results presented are means of quadruplicate determinations. Figure 1 shows the variation of weight loss with time in the uninhibited and inhibited $1 \mathrm{M} \mathrm{HCl}$. The result shows that FE extract effectively inhibited mild steel corrosion at all the concentrations studied. Figure 2 (a) shows the variation of inhibition efficiency with time for mild steel corrosion in the presence of different concentrations of FE and Figure 2 (b) shows the variation of inhibition efficiency with FE concentrations after $24 \mathrm{~h}$ of immersion. The result in Figure 2 (a) shows that efficiency

Table 1. Inhibition efficiency of FE extract on mild steel corrosion in $1 \mathrm{M} \mathrm{HCl}$

\begin{tabular}{lllllll}
\hline $\begin{array}{l}\text { System } \\
(\mathrm{mg} / \mathrm{L}) \mathrm{FE}\end{array}$ & $\begin{array}{l}24 \mathrm{~h} \\
\mathrm{IE} \%\end{array}$ & $\begin{array}{l}48 \mathrm{~h} \\
\mathrm{IE} \%\end{array}$ & $\begin{array}{l}72 \mathrm{~h} \\
\mathrm{IE} \%\end{array}$ & $\begin{array}{l}96 \mathrm{~h} \\
\mathrm{IE} \%\end{array}$ & $\begin{array}{l}120 \mathrm{~h} \\
\mathrm{IE} \%\end{array}$ & $\begin{array}{l}336 \mathrm{~h} \\
\mathrm{IE} \%\end{array}$ \\
\hline 50 & 74.3 & 73.5 & 72.2 & 71.2 & 65.5 & 55.2 \\
200 & 78.3 & 76.1 & 75.8 & 73.3 & 72.5 & 60.5 \\
400 & 83.5 & 79.9 & 78.6 & 76.7 & 76.4 & 71.9 \\
600 & 85.2 & 83.5 & 81.7 & 79.9 & 78.5 & 72.5 \\
800 & 86.2 & 84.3 & 82.5 & 81.5 & 79.2 & 74.2 \\
1000 & 87.7 & 85.2 & 83.5 & 82.3 & 80.1 & 75.8 \\
1500 & 90.1 & 88.3 & 86.5 & 85.2 & 80.5 & 79.5 \\
\hline
\end{tabular}

Reduced with increase in exposure time and that FE extract maintained good inhibition efficiency even at $336 \mathrm{~h}$. The least inhibition efficiency observed was $55.2 \%$ at a concentration of $50 \mathrm{mg} / \mathrm{L}$ at $336 \mathrm{~h}$. The result in 2 (b) shows that inhibition efficiency increased with FE concentration. Table 1 presents the calculated inhibition efficiencies as a function of both FE concentration and immersion time. The result shows that inhibition efficiency increased with increase in FE concentration and reduced with increase in exposure time. It can also be observed from the result that FE extract is an efficient corrosion inhibitor for mild steel in $1 \mathrm{M} \mathrm{HCl}$ even after $336 \mathrm{~h}$ of immersion. Inhibition efficiency from the gravimetric experiment was estimated as follows;

$$
\mathrm{IE}_{\mathrm{W}} \%=\left(1-\frac{\Delta \mathrm{Winh}}{\Delta \text { Wblank }}\right) \mathrm{X} 100 .
$$

Where $\Delta \mathrm{W}_{\text {blank }}$ and $\Delta \mathrm{W}_{\text {inh }}$ are the weight loss of mild steel in the absence and presence of inhibitor, respectively. Figure 3 shows the variation of weight loss with concentration, the result shows that the FE extracts diminished the corrosion rate of mild steel in $1 \mathrm{M} \mathrm{HCl}$.

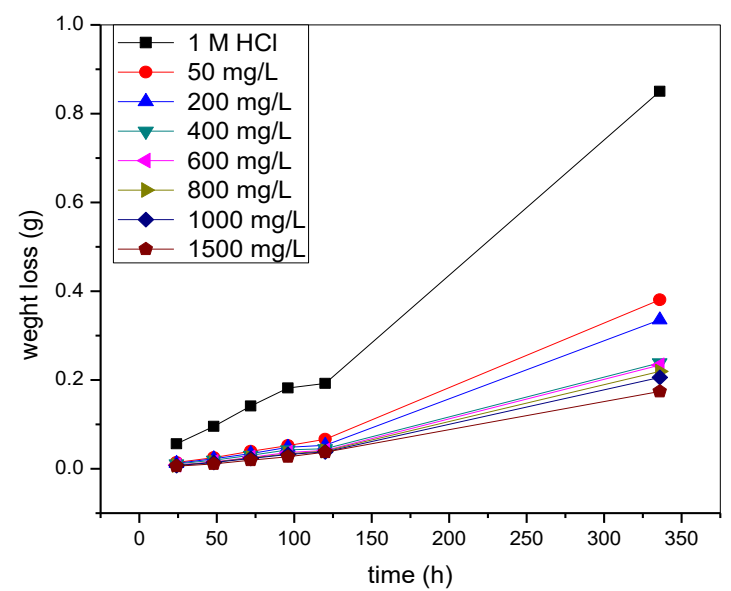

Figure 1. Variation of weight loss with time for mild steel corrosion in $1 \mathrm{M} \mathrm{HCl}$ solution in the absence and presence of ethanol extract of FE. 


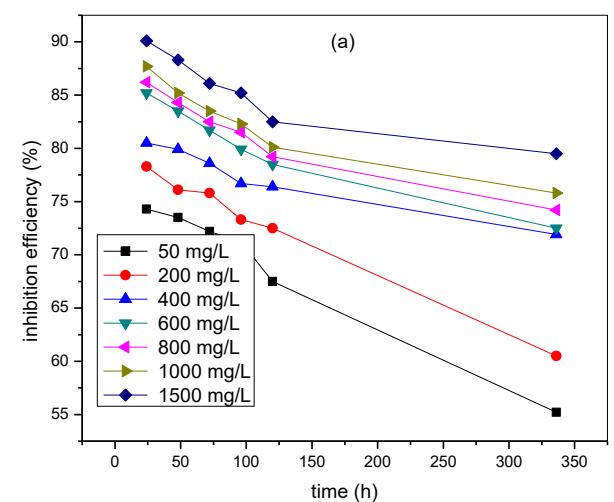

Figure 2. Variation of inhibition efficiency with (a) time for mild steel corrosion in $1 \mathrm{M} \mathrm{HCl}$

solution in the presence of ethanol extract of FE (b) FE concentration for mild steel corrosion in 1 $\mathrm{M} \mathrm{HCl}$ after $24 \mathrm{~h}$.

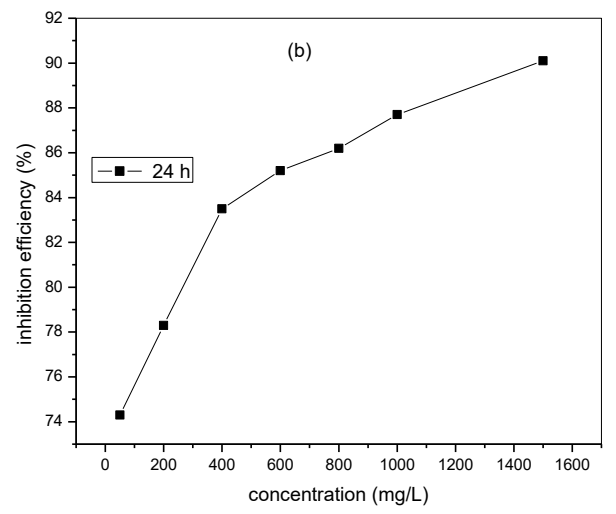

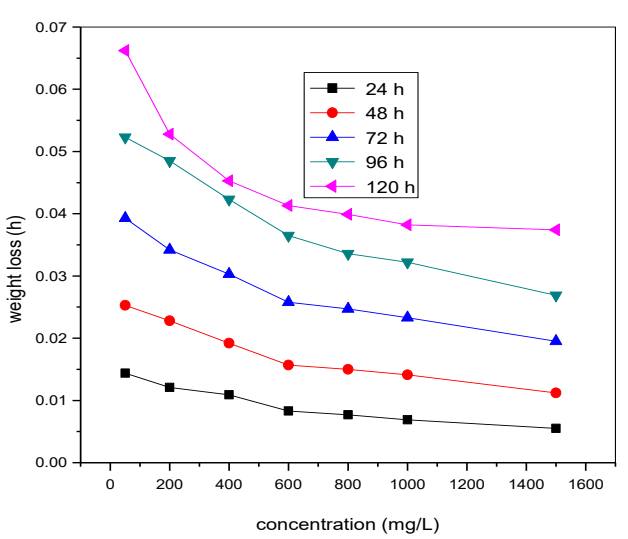

Figure 3. Variation of weight loss with concentration for mild steel corrosion in $1 \mathrm{M} \mathrm{HCl}$ solution in the absence and presence of ethanol extract of FE.

\section{Electrochemical Results:}

Electrochemical impedance results: Electrochemical experiments were undertaken to study the inhibitive effects of FE extract on mild steel corrosion from an electrochemical point of view. The chosen concentrations for the electrochemical experiments are $(50 \mathrm{mg} / \mathrm{L}, 600 \mathrm{mg} / \mathrm{L}$ and $1500 \mathrm{mg} / \mathrm{L}$, these concentrations were chosen to cover the concentration range used for the gravimetric experiment. Nyquist plot for mild steel corrosion in $1 \mathrm{M} \mathrm{HCl}$ in the absence and presence of $50 \mathrm{mg} / \mathrm{L}, 600 \mathrm{mg} / \mathrm{L}$ and $1500 \mathrm{mg} / \mathrm{L} \mathrm{FE}$ extracts are shown in figure 4. The Nyquist plot show single semicircles for all systems over the frequency range studied. The high frequency intercept with the real axis in the Nyquist plots assigned to the solution resistance $\left(R_{S}\right)$ and the low frequency intercept with the real axis ascribed to the charge transfer resistance $\left(R_{c t}\right)$. Figure 4 shows gradual increase in the size of the semicircle with increase in FE concentration. the impedance spectra were analyzed by fitting to the equivalent circuit models $R_{\mathrm{s}}\left(\mathrm{Q}_{\mathrm{dl}} \mathrm{R}_{\mathrm{ct}}\right)$ which has been used previously to model impedance spectra $[25,26]$. Table 2 embodies various impedance parameters such as charge transfer resistance $\left(\mathrm{R}_{\mathrm{ct}}\right)$, double layer capacitance $\left(\mathrm{Q}_{\mathrm{dl}}\right)$ and inhibition efficiency $\mathrm{IE}_{\mathrm{I}} \%$. A gradual decrease in the values of $\left(\mathrm{Q}_{\mathrm{dl}}\right)$ with increase in the concentration of $\mathrm{FE}$ extracts was observed. This considerable decrease in the size of $\left(\mathrm{Q}_{\mathrm{dl}}\right)$ has confirmed that $\mathrm{FE}$ molecules were adsorbed on the mild steel surface and has decreased the roughness of the metal surface created due to corrosion by $1 \mathrm{HCl}$ solution. The values of the inhibition efficiency were calculated from the impedance data as follows:

$$
\mathrm{IE}_{\mathrm{I}} \%=\left(\frac{\text { Rct,inh-Rct, } \mathrm{bl}}{\text { Rct,inh }}\right) \times 100 .
$$


Where $R_{c t, b l}$ and $R_{c t, \text { inh }}$ are the charge transfer resistance values in the absence and presence of the inhibitor respectively.

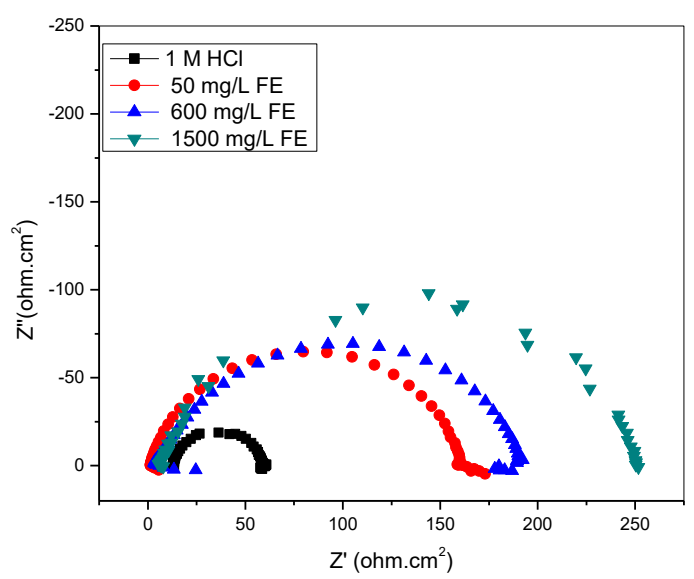

Figure 4. Nyquist plot for mild steel corrosion in $1 \mathrm{M} \mathrm{HCl}$ without and with FE extracts.

To calculate the values of Qdl, the frequency $\left(f_{\max }\right)$ at which the imaginary component of the impedance is maximum $-Z_{\mathrm{im}(\max )}$ was found and Qdl was obtained from the equation below:

$$
\mathrm{Qdl}=\frac{1}{2 \pi \mathrm{fmax} R c t}
$$

Table 2. Impedance Results for mild steel Corrosion in $1 \mathrm{M} \mathrm{HCl}$ without and with FE extracts.

\begin{tabular}{lllll}
\hline System $(\mathrm{mg} / \mathrm{L})$ & $\mathrm{R}_{\mathrm{ct}}\left(\Omega \mathrm{cm}^{2}\right)$ & $\begin{array}{l}\mathrm{Q}_{\mathrm{dl}}\left(\mu \Omega^{-1} \mathrm{~S}^{\mathrm{n}} \mathrm{cm}^{-2}\right) \\
\mathrm{x} 10^{-4}\end{array}$ & $\mathrm{n}$ & $\mathrm{IE}_{\mathrm{I}} \%$ \\
\hline HCl blank & 46.1 & 1.38 & 0.9116 & \\
FE 50 mg/L & 155.4 & 0.53 & 0.9292 & 70.4 \\
FE $600 \mathrm{mg} / \mathrm{L}$ & 169.5 & 0.47 & 0.9012 & 72.8 \\
FE $1500 \mathrm{mg} / \mathrm{L}$ & 261.4 & 0.31 & 0.8078 & 82.4 \\
\hline
\end{tabular}

Potentiodynamic polarization results: Potentiodynamic polarization experiments were undertaken to identify the effect of FE extract on the anodic dissolution of mild steel and the cathodic reduction of hydrogen ion. Typical potentiodynamic polarization curves for mild steel corrosion in $1 \mathrm{M} \mathrm{HCl}$ in the absence and presence of 50,600 and $1500 \mathrm{mg} / \mathrm{L}$ of FE extracts are given in figure 5 while the electrochemical parameters derived from the polarization curves is given in table 3 . From the results it can be seen that the addition of the FE extracts affected the anodic as well as the cathocic half reactions, shifting the corrosion potential (Ecorr) slightly towards more negative (cathodic) values and reducing the anodic and cathodic current densities and also the reaction corrosion current density (icorr).From the results obtained it can be said the FE extracts functioned as mixed type corrosion inhibitor for mild steel in $1 \mathrm{M} \mathrm{HCl}$. The value of the inhibition efficiency was calculated from the polarization parameters using the equation below:

$$
I E p \%=\left(\frac{I_{\operatorname{corr}(b l)}-I_{\operatorname{corr}(i n h)}}{I_{\operatorname{corr}(b l)}}\right) \times 100
$$

Where Icorr (bl) and Icorr (inh) represents the corrosion current density in the absence and presence of the inhibitor, respectively 


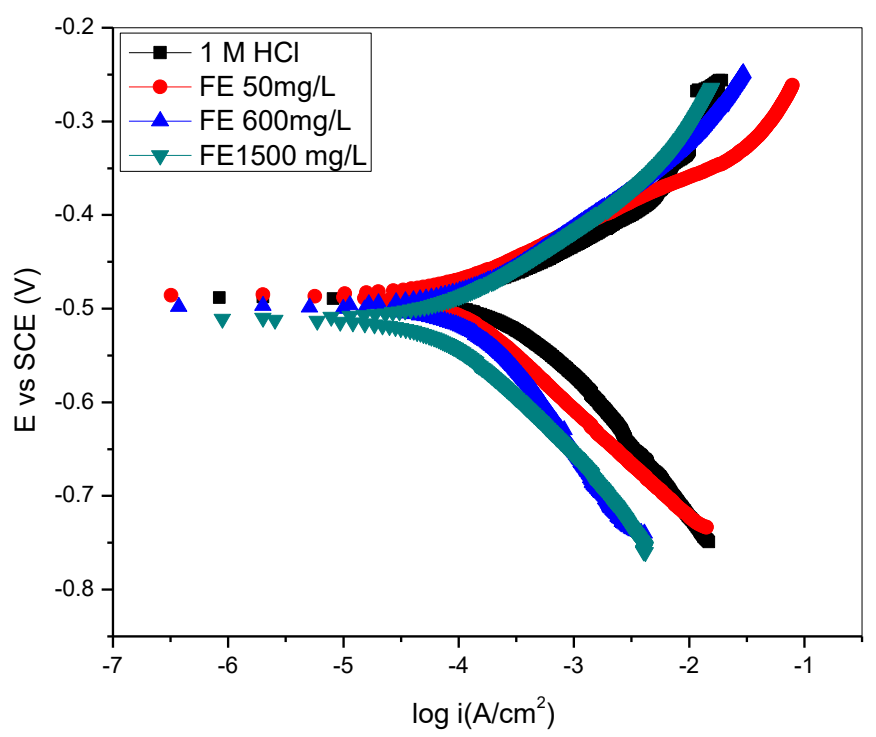

Figure 5. Potentidynamis polarization curves of mild steel corrosion in $1 \mathrm{M} \mathrm{HCl}$ solution without and with FE extracts.

Table 3. Potentiodynamic polarization parameters for mild steel corrosion in $1 \mathrm{M} \mathrm{HCl}$ with and without FE extracts

\begin{tabular}{llll}
\hline System $(\mathrm{mg} / \mathrm{L})$ & $\mathrm{E}(\mathrm{mV}$ vs SCE $)$ & $\mathrm{i}_{\text {corr }}\left(\mu \mathrm{A} / \mathrm{cm}^{2}\right)$ & $\mathrm{IE}_{\mathrm{P}} \%$ \\
\hline $1 \mathrm{M} \mathrm{HCl}$ (blank) & -488.3 & 49.28 & \\
$50 \mathrm{mg} / \mathrm{L}$ & -484.7 & 3.23 & 93.5 \\
$600 \mathrm{mg} / \mathrm{L}$ & -481.8 & 2.85 & 94.2 \\
$1500 \mathrm{mg} / \mathrm{L}$ & -480.2 & 1.06 & 97.9 \\
\hline
\end{tabular}

From table 3 , It is observed that the $\mathrm{i}_{\text {corr }}$ values gradually decreased with gradual increase in the concentration of FE up to $1500 \mathrm{mg} / \mathrm{L}$ from $3.23\left(\mu \mathrm{A} / \mathrm{cm}^{2}\right)$ in $50 \mathrm{mg} / \mathrm{L}$ to $1.06\left(\mu \mathrm{A} / \mathrm{cm}^{2}\right)$ in 1500 $\mathrm{mg} / \mathrm{L}$ leading to increase in inhibition efficiency from $93.5 \%$ to $97.9 \%$.The obtained values from table 3 can be seen to follow the same trend as the gravimetric and impedance data therefore highlighting the corrosion inhibiting efficacy of FE extracts.

Adsorption consideration: The inhibitive action of organic components present in the FE extracts is attributed to the adsorption of the FE extracts on the mild steel surface as already observed in the electrochemical impedance spectroscopy experiment. The adsorbed layer acts as a barrier preventing both mass and charge transfer leading to a reduction in the rate of mild steel corrosion. Further characterization of adsorption involved fitting the experimental data in frequently used adsorption isotherms. The fraction of the surface covered by adsorbed molecule (surface coverage) represented by $\theta$ is an indication of the effectiveness of the adsorbed specie and is directly proportional to the inhibition efficiency (IE). $\theta$ can be calculated from the inhibition efficiency from the equation below: [27]

$$
\theta=\mathrm{IE} / 100
$$

Different adsorption isotherms were tried but it was observed that the best fit isotherm for this experiment is the Langmuir adsorption isotherm as determined from the gravimetric measurement after $24 \mathrm{~h}$ of immersion. 
According to the Langmuir adsorption isotherm,

$$
C / \theta=1 / b+C
$$

Where $\mathrm{C}$ is the inhibitor concentration, $\mathrm{b}$ is the equilibrium constant and $\theta$ is the degree of surface coverage

The plot of $C / \theta$ versus $\mathrm{C}$ is shown in figure 6 to be linear for $\mathrm{FE}$ extract in $1 \mathrm{M} \mathrm{HCl}$ solution: with slope 1.097 and $\mathrm{R}^{2}$ value of 0.99894 suggesting that the experimental data follows the Langmuir adsorption isotherm.

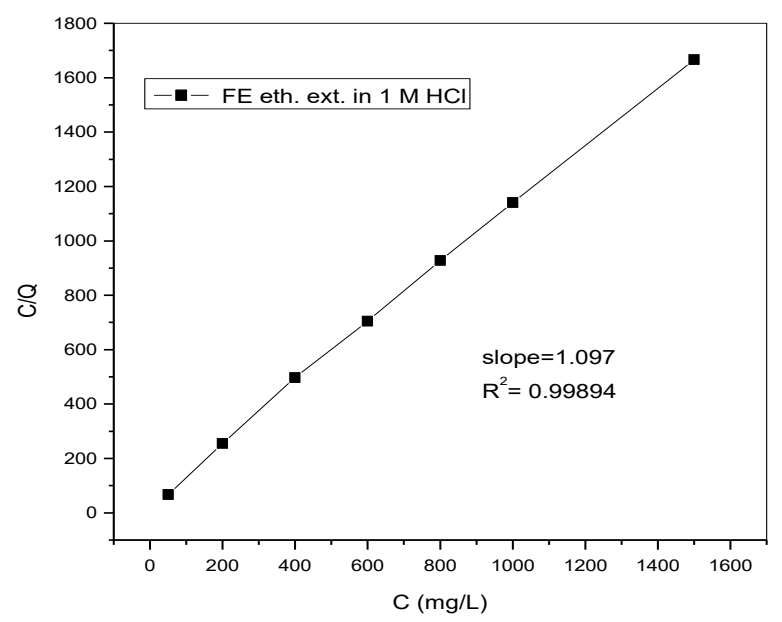

Figure 6. Langmuir adsorption isotherm for FE extracts on mild steel in $1 \mathrm{M} \mathrm{HCl}$.

\section{Fourier Transformed Infrared Spectroscopy Analysis:}

The FTIR spectra of FE powder before and after extraction as well as that of the scrapings from the inhibitor films formed on the surface of mild steel after $3 \mathrm{~h}$ immersion in $1 \mathrm{M} \mathrm{HCl}$ solution containing $1500 \mathrm{mg} / \mathrm{L}$ of FE extract is presented in figure 7.

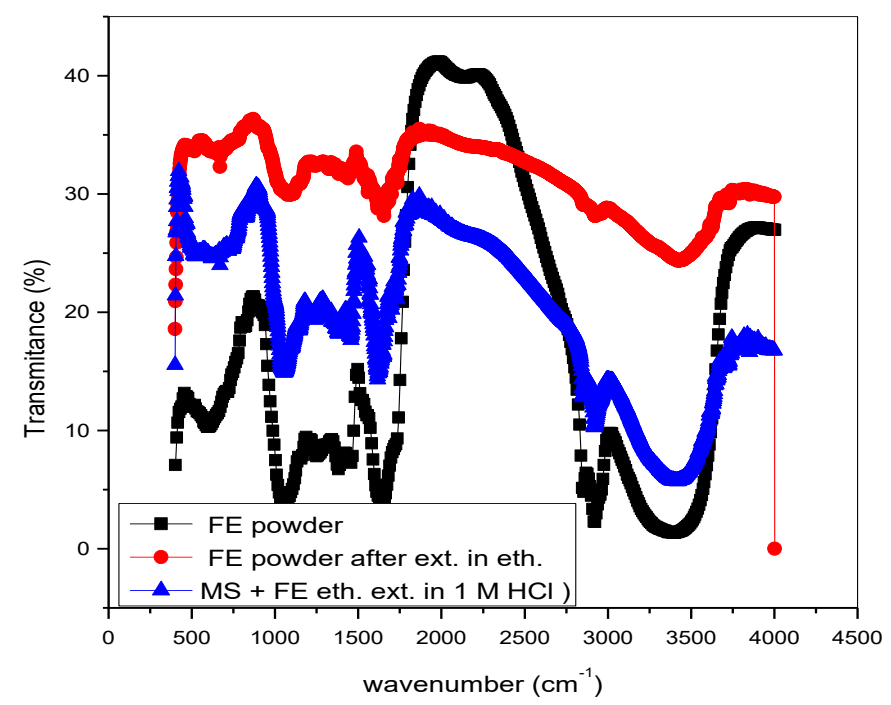

Figure 7. FTIR spectra of FE powder before and after extraction in ethanol and the surface film on mild steel specimens immersed in $1 \mathrm{M} \mathrm{HCl}$ solution containing FE powder.

Examination of the plot in Figure 6a reveals the presence of some peaks; which is attributed to the existence of functional groups. Most of the peaks in FE powder before and after extraction are also observed for the film adsorbed on the mild steel surface, confirming the existence of these 
functional groups in the inhibitor film adsorbed on the steel surface. Some of the peaks deviated, while some vanished. We observed a shift from 1648 to $1604 \mathrm{~cm}^{-1}$ due to the $\mathrm{C}=\mathrm{O}$ stretching, the bands related to $\mathrm{O}-\mathrm{H} / \mathrm{N}-\mathrm{H}$ at 3209 shifts to $3320 \mathrm{~cm}^{-1}$, those associated with $\mathrm{C}-\mathrm{N}$ at 1002 vanished. The shift of $\mathrm{C}=\mathrm{C}$ and $\mathrm{C}-\mathrm{O}$ stretching frequencies from 1650 to $1636 \mathrm{~cm}^{-1}$ and from 1250 to 1083 $\mathrm{cm}^{-1}$, respectively, suggests the adsorption of FE molecules on the corroding metal surface. The shift due to $\mathrm{O}-\mathrm{H} / \mathrm{N}-\mathrm{H}$ and $\mathrm{C}=\mathrm{O}$ stretching frequencies from 3209 to $3386 \mathrm{~cm}^{-1}$ and from 1723 to $1703 \mathrm{~cm}^{-1}$ also confirm the adsorption of the inhibitor species on the metal surface.

\section{Theoretical considerations}

Our experimental results have shown that the Corrosion inhibition of mild steel by the ethanol extract of FE occurred through the adsorption of the inhibitor organic matter on the metal surface. The contributions of the individual molecules to the overall adsorption process could not be achieved experimentally. We therefore rely on performing theoretical computations in the framework of the density functional theory (DFT) and molecular dynamic simulation to theoretically overcome this problem. Density functional theory (DFT) has been used to calculate information relating molecular geometries and electron distributions, which influence corrosion inhibition performance $[28,29]$. The structures of some major constituents of FE were modeled using a combination of DFT- based quantum chemical calculations and molecular dynamics simulations to theoretically evaluate the inhibiting potential based on structure-activity relationship to determine basic molecular descriptors. Three major constituents of FE modeled are Ascorbic acid, Methyl ursolate and N,N-Dimethylcon-5-enin-3-amine.The simulations were performed by means of density functional theory (DFT) electronic structure program $\mathrm{DMol}^{3}$ using a Mulliken population analysis [30,31]. Electronic parameters for the simulation include restricted spin polarization using the DND basis set and the Perdew-Wang (PW) local-correlation-density functional. The molecular structures were first subjected to geometry optimization using a COMPASS force field and the Smart minimization method by high-convergence criteria, more geometrical optimization of the molecules were carried out using neglect of diatomic differential overlap (NDDO) with AM1 Hamiltonian in the semi empirical molecular orbital package VAMP (MS Studio 4.0). The electronic structures of the molecules, including the distribution of frontier molecular orbital and Fukui indices were then determined.

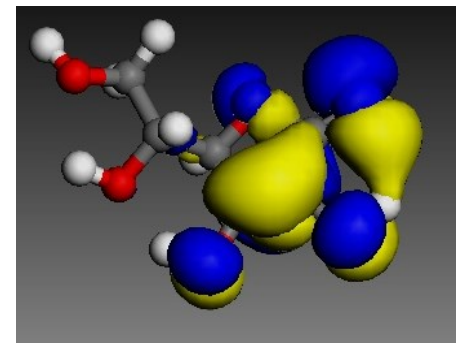

(a)

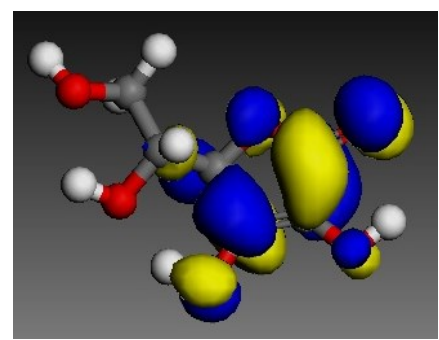

(b)

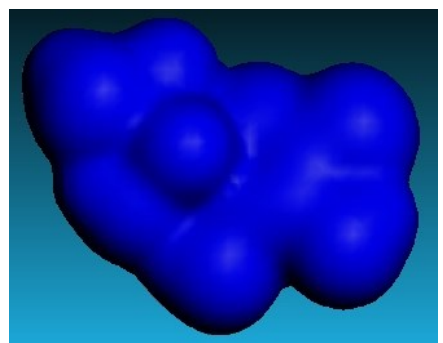

(c)

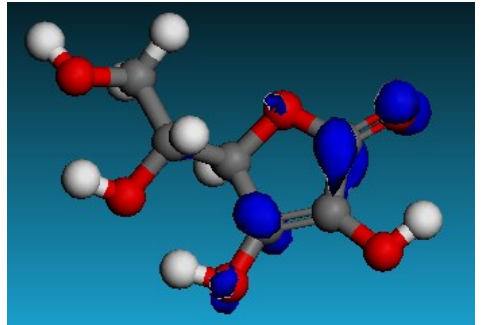

(d)

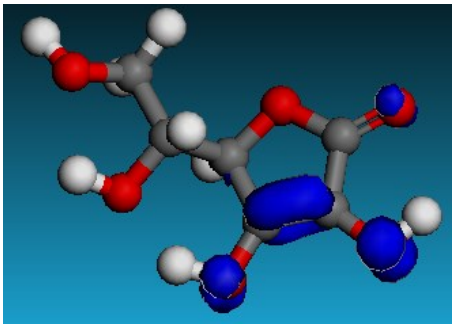

(e)

Figure 8. Electronic properties of ascorbic acid (a) HOMO orbital (b) LUMO orbital (c) total electron density (d) $\mathrm{F}^{+}$(e) $\mathrm{F}^{-}$. Atom legend: white $=\mathrm{H}$; gray $=\mathrm{C}$; red $=\mathrm{O}$; blue $=\mathrm{N}$. The blue and yellow isosurfaces depict the electron density difference: the blue regions show electron accumulation while the yellow regions show electron loss. 


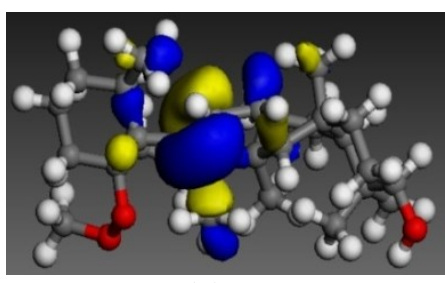

(a)

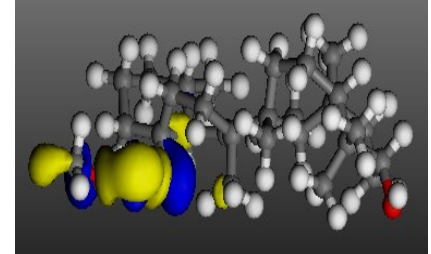

(b)

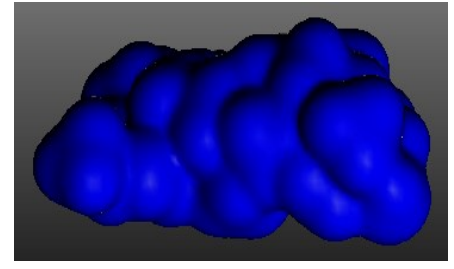

(c)

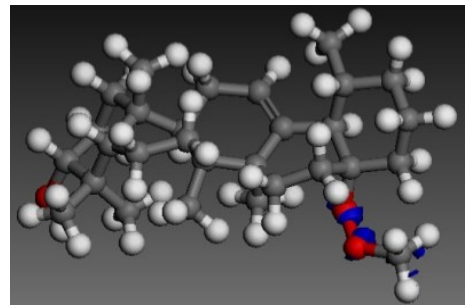

(d)

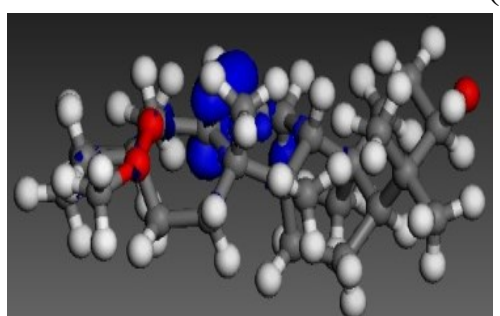

(e)

Figure 9. Electronic properties of Methyl ursolate (a) HOMO orbital (b) LUMO orbital (c) electron density (d) $\mathrm{F}^{+}$(e) $\mathrm{F}^{-}$. Atom legend: white $=\mathrm{H}$; gray $=\mathrm{C}$; red $=\mathrm{O}$; blue $=\mathrm{N}$. The blue and yellow isosurfaces depict the electron density difference: the blue regions show electron accumulation while the yellow regions show electron loss.

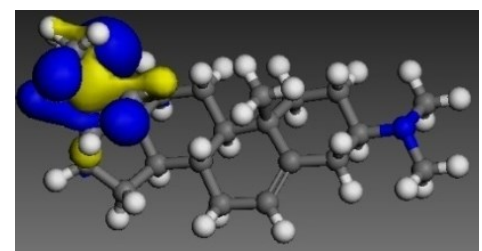

(a)

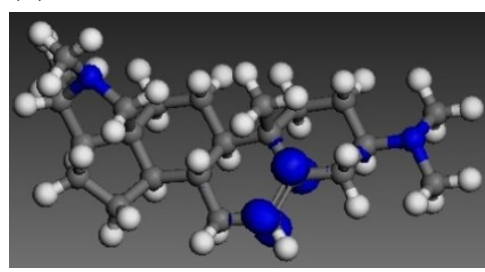

(d)

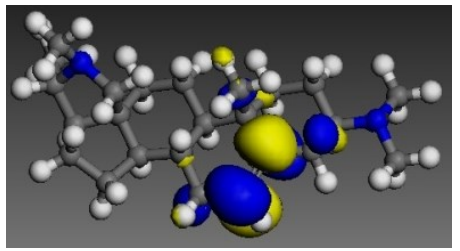

(b)

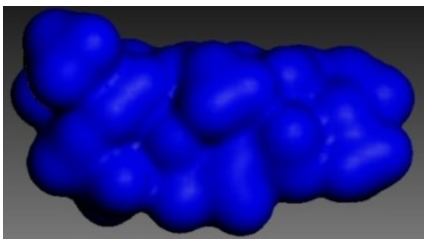

(c)

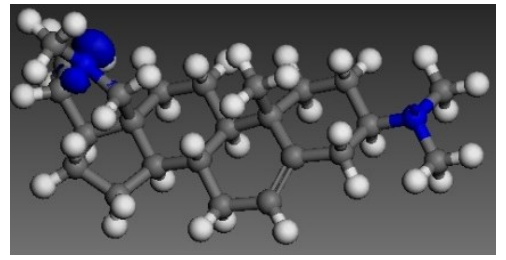

(e)

Figure 10. Electronic properties of N,N-Dimethylcon-5-enin-3-amine ursolate (a) HOMO orbital (b) LUMO orbital (c) electronic structure (d) $\mathrm{F}^{+}$(e) $\mathrm{F}^{-}$. Atom legend: white $=\mathrm{H}$; gray $=\mathrm{C}$; red $=\mathrm{O}$; blue $=\mathrm{N}$. The blue and yellow isosurfaces depict the electron density difference: the blue regions show electron accumulation while the yellow regions show electron loss. 


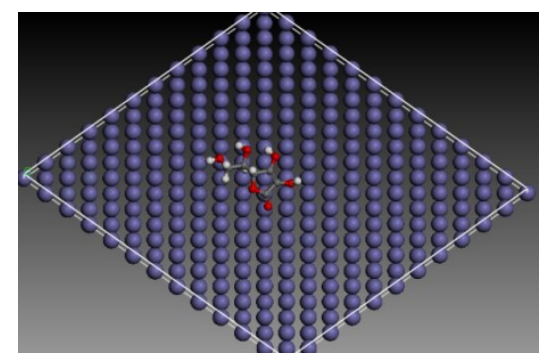

(a)

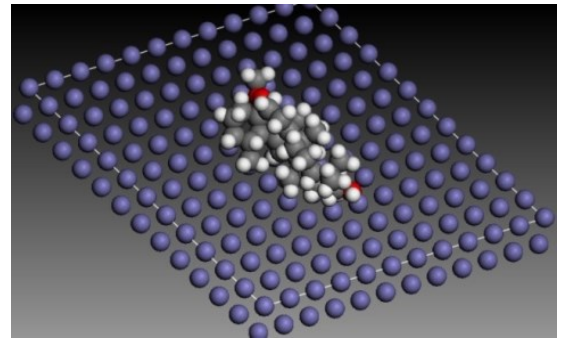

(b)

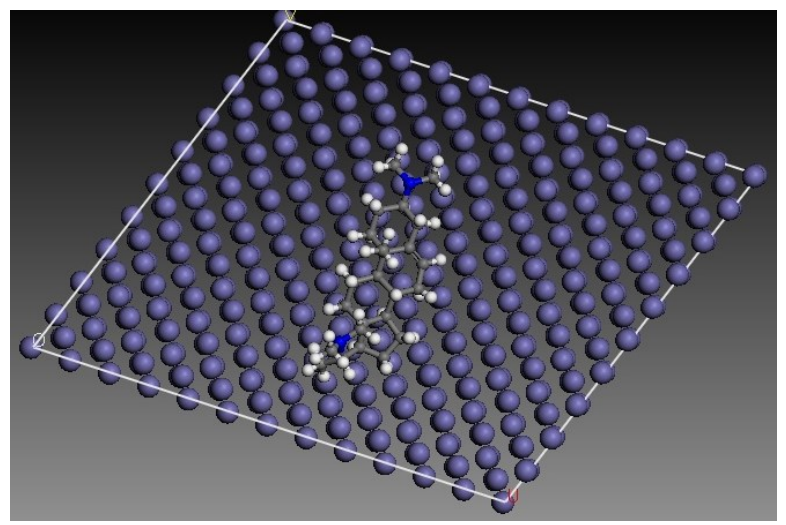

(c)

Figure 11. Top view of the representative snapshots from molecular dynamics models of: (a) ascorbic acid, (b) methyl ursolate and (c) N,N-Dimethylcon-5-enin-3-amine

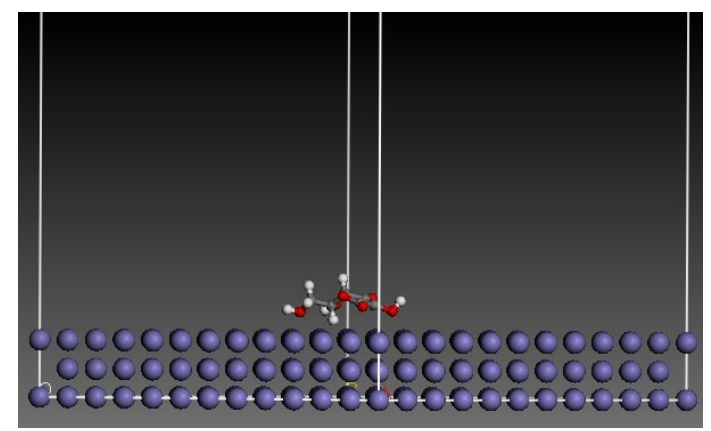

(a)

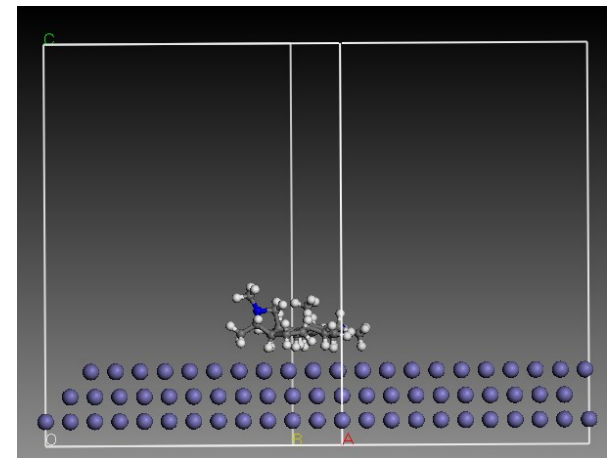

(b)

Figure 12. Side view of the representative snapshots from molecular dynamics models of: (a) ascorbic acid, (b) N,N-Dimethylcon-5-enin-3-amine

Figure 8 (a-e), shows the highest occupied molecular orbital (HOMO), lowest unoccupied molecular orbital (LUMO), the total electron density, center for electrophilic behavior $\left(\mathrm{F}^{-}\right)$and center for nucleophilic behavior $\left(\mathrm{F}^{+}\right)$of ascorbic acid, whereas figures 9 and 10 show similar properties for methyl ursolate and N,N-Dimethylcon-5-enin-3-amine respectively. The electron density can be seen to saturate all around each molecule: Which facilitate flat lying adsorption orientations. The regions of highest occupied molecular orbital (HOMO) and the lowest unoccupied molecular orbitals also called the frontier orbitals determine the way the molecule interact with other species. The HOMO is the orbital that acts as an electron donor since it is the outermost orbital containing electron. The LUMO is the orbital that acts as an electron acceptor, since it is the innermost orbital that could act as electron acceptor. According to the frontier molecular orbital, the formation of the transition state is due to the interaction between the frontier orbitals of reaction [32]. A large HOMO-LUMO gap implies high stability for the molecule in chemical reactions.

The eigenvalues of the HOMO ( $\left.\mathrm{E}_{\mathrm{HOMO}}\right)$, LUMO ( $\left.\mathrm{E}_{\mathrm{LUMO}}\right)$ and the energy gap $\Delta \mathrm{E}=\mathrm{E}_{\mathrm{LUMO}} \mathrm{HOMO}$ are presented in table 4, as well as other quantum chemical parameters related to the molecular electronic structure of the most stable conformation of the molecules. High values of $\mathrm{E}_{\mathrm{HOMO}}$ indicate the ability of the molecule to donate electrons to an appropriate acceptor, also low value of 
$\Delta \mathrm{E}$ will favor good inhibition efficiency since the energy needed to remove an electron from the last occupied orbital will be reduced [33,34]

I and $\mathrm{A}$ are related to $\mathrm{E}_{\mathrm{HOMO}}$ and $\mathrm{E}_{\mathrm{LUMO}}$ according to the equation:

$$
\mathrm{I}=-\mathrm{E}_{\text {Hомо }}, \mathrm{A}=-\mathrm{E}_{\mathrm{LUMO}} .
$$

The absolute electronegativity $(\chi)$, absolute hardness $(\eta)$ and softness $(\sigma)$ of the molecules were calculated using the equation:

$$
\begin{aligned}
& X=\frac{I+A}{2} \\
& \eta=\frac{I-A}{2} \\
& \sigma=\frac{I}{\eta}
\end{aligned}
$$

Electron charge transfer, $(\Delta \mathrm{N})$ from Lewis base (the inhibitor) to Lewis acid (the metal surface) was quantified using the equation below

$$
\Delta \mathrm{N}=\frac{\mathrm{Xm}-\mathrm{Xi}}{2(\eta \mathrm{m}+\eta \mathrm{i})}
$$

Where $X_{m}$ and $X_{i}$ are the absolute electronegativity of the metal and inhibitor molecule, respectively, $\eta_{\mathrm{m}}$ and $\eta_{\mathrm{i}}$ are the absolute hardness of the metal and inhibitor molecule respectively. The $\Delta \mathrm{N}$ values presented in table 4 were calculated using theoretical values of $7 \mathrm{eV} / \mathrm{mol}$ and 0 $\mathrm{eV} / \mathrm{mol}$ for $\mathrm{X}_{\mathrm{m}}$ and $\eta_{\mathrm{m}}$ respectively [35]. $\Delta \mathrm{N}$ values has been reported to increase with increase in inhibition efficiency[36].

Table 4. Calculated quantum chemical properties for the most stable configuration of ascorbic acid, methyl ursolate and N,N-Dimethylcon-5-enin-3-amine.

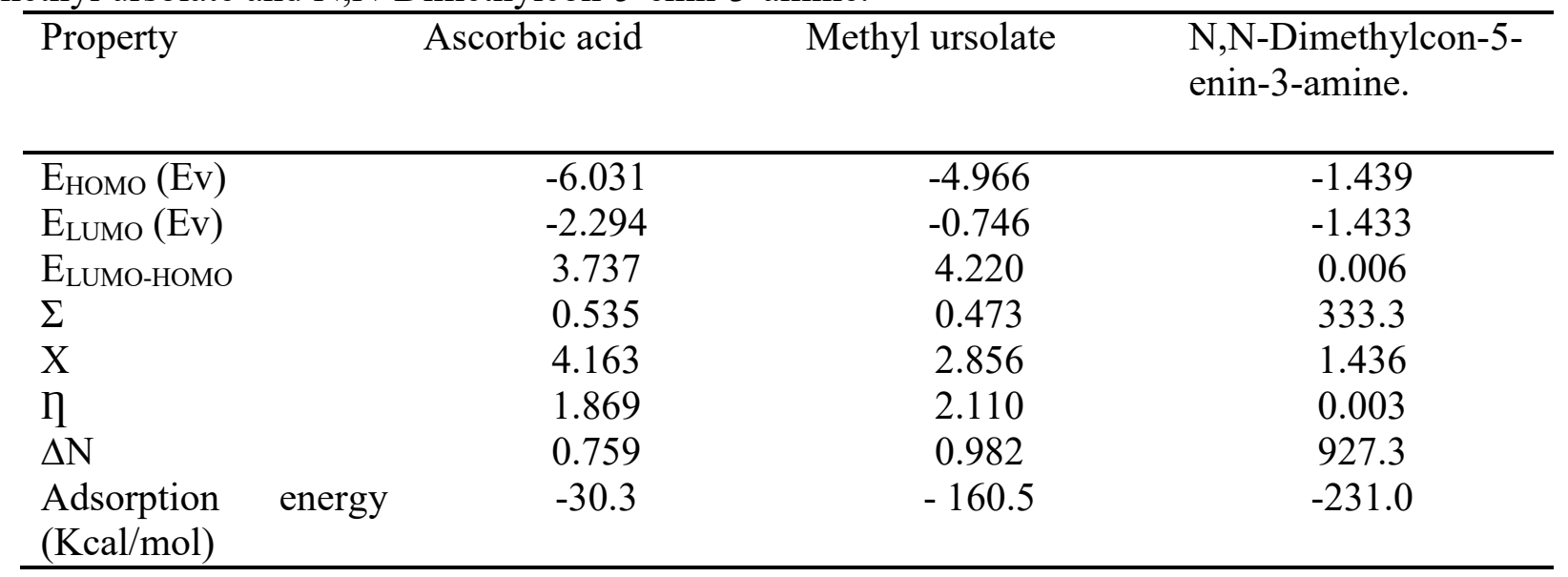

The results show that N,N-Dimethylcon-5-enin-3-amine has the highest value of $\mathrm{E}_{\mathrm{HOMO}}$ and the lowest value of $\Delta \mathrm{E}$ therefore it may be said to be more stable than the other molecules.

Molecular dynamics simulation was used to sample different low energy adsorption configurations of the molecules on the Fe surface using Force quench molecular dynamics to sample many different low energy configurations and identify the low-energy minima. The Fe slab was cleaved along the (110) plane. The calculations were performed in a 12 × 10 supercell using a Compass force field and the Smart algorithm with NVE (microcanonical) ensemble, a time step of 1 
fs and simulation time of 5 ps. system was quenched automatically at intervals of 250 steps while maintaining the temperature at $303 \mathrm{~K}$.

Figure11(a-c) shows top view of the representative snapshots of the lowest energy adsorption configurations for single molecules of ascorbic acid, methyl ursolate and N,N-Dimethylcon-5-enin3 -amine respectively on the Fe (110) surface from our simulations. Figure12 show the side view positions for ascorbic acid and N, N-Dimethylcon-5-enin-3-amine. Each molecule is seen to maintain flat lying adsorption orientation on the Fe surface as expected from the delocalization of the electrons on the molecules. This adsorption position maximizes contact between the molecule and the Fe surface and then improves surface coverage.

In order to quantify the interaction between the molecules under study and the Fe surface, the binding energy $\left(\mathrm{E}_{\text {bind }}\right)$ of each system was calculated using the equation:

$$
\mathrm{E}_{\text {bind }}=\mathrm{E}_{\text {total }-}\left(\mathrm{E}_{\mathrm{inh}}+\mathrm{E}_{\mathrm{Fe}}\right) \text {. }
$$

Where $\mathrm{E}_{\mathrm{inh}}, \mathrm{E}_{\mathrm{Fe}}$ and $\mathrm{E}_{\text {total }}$ denotes the total energy of the single molecule, the Fe slab without adsorption and the total energy of the system containing the molecule/Fe surface, respectively. The total energies were obtained by averaging the energies of the five most stable adsorption configurations. the obtained values of $E_{a d s}$ values are -30 for ascorbic acid, -160.5 for methyl ursolate and -231.0 for N,N-Dimethylcon-5-enin-3-amine all the adsorption energies are all negative indicating stable adsorption structures. The trend in adsorption energy correspond to the trend in molecular size obtained earlier (N, N-Dimethylcon-5-enin-3-amine > methyl ursolate $>$ ascorbic acid) showing that the larger molecules adsorb better that smaller ones.

The calculated values are presented in Table 3. Good linear correlation has been found to exist between inhibition efficiency and binding energy, wherein efficiency increased with binding energy [37].

\section{Conclusion}

From the result of this research, it has been established the ethanol extract of Funtumia elastic (FE) is an adsorption inhibitor mild steel in $1 \mathrm{M} \mathrm{HCl}$ solution. The gravimetric results showed that inhibition efficiency decreased with increase in exposure time but maintained high inhibition efficiency even at long exposure time $(336 \mathrm{~h})$. Polarization study revealed that the inhibitor is a mixed type corrosion inhibitor for mild steel in $1 \mathrm{M} \mathrm{HCl}$ solution. The FTIR results indicate that FE extract functioned by the adsorption of the organic matter on the corroding mild steel surface. Quantum chemical calculations performed on some active components of FE confirmed their strong contribution the overall inhibiting process.

\section{References}

[1] A. Bouyanzer, and B. Hammouti, Naturally occurring ginger as corrosion inhibitor for steel in molar hydrochloric acid at $353 \mathrm{~K}$, Bull Electrochem., 20 (2004) 63-65.

[2] E. El Quariachi, J. P.Paolini, A. Elidrissi, A. Bouyanzer, B. Hammouti, and J.M. Desjobert, Adsorption properties of Rosmarinus of ficinalis oil as green corrosion inhibitors on C38 steel in $0.5 \mathrm{M} \mathrm{H}_{2} \mathrm{SO}_{4}$, J. of Costa, Acta Mettallurgica Sinica, 23 (2010) 13-20.

[3] C. O. Akalezi, C. K. Enenebaku, and E.E. Oguzie, Inhibition of acid corrosion of mild steel by Biomass extract from the petersianthus macrocarpus plant, J.Mater. Environ. Sci. 4 (2013) 217-226.

[4] M. R. Singh, A green approach: A corrosion inhibition of mild steel by Adhatoda vasica plant extract in $0.5 \mathrm{M} \mathrm{H}_{2} \mathrm{SO}_{4}$ J. Mater. Environ. Sci. 4 (2013) 117-126.

[5] O. Benali, H. Benmehdi, O. Hasnaoui, C. Selles and R. Salghi, Green corrosion inhibitor: inhibitive action of tannin extract of chamaerops humilis plant for the corrosion of mild steel in 0.5 $\mathrm{M} \mathrm{H}_{2} \mathrm{SO}_{4}$, J. Mater. Environ. Sci. 4 (2013) 127-138.

[6] E. Chaieb, A. Bouyanzer, B. Hammouti M. Benkaddour, and M. Berrabah, Corrosion inhibition of iron in hydrochloric acid solutions by rosemary oil. Trans. SAEST, 39 (2004) 58-60. 
[7] G. Moretti, F. Guidi, and G. Grion, Tryptamine as a green iron corrosion inhibitor in $0.5 \mathrm{M}$ desecrated sulphuric acid Corros. Sci. 46 (2004) 387-403.

[8] L. Tang, G. Mu, and G. Liu, The effect of neutral red on the corrosion inhibition of cold rolled steel in 1 M hydrochloric acid, Corros. Sci. 45 (2003) 2251-2262.

[9] E.E. Oguzie, Y. Li, and F.H. Wang, Corrosion inhibition and adsorption behavior of methionine on mild steel in sulfuric acid and synergistic effect of iodine ion, J. Colloid Interface Sci. 310 (2007) 90-98.

[10] M.S. Morad, and A.M. Kamal El- Dean, 2,2'-Dithiobis(3-cyano-4,6-dimethylpyridine): A new class of acid corrosion inhibitors for mild steel, Corros. Sci. 48 (2006) 3398-3412.

[11] M. A. Chidiebere, C. E. Ogukwe, K. L. Oguzie, C. N. Eneh, and E. E. Oguzie, corrosion Inhibition and adsorption behaviuor of Punuca granatum extract on mild steel in acidic Environments: Experimental and theoretical studies, Ind. Eng. Chem. Res. 51, (2012) 668-677.

[12] U.J. Ekpe, E.E. Ebenso and U.J. Ibok, Inhibitory action of Azadirachta indica leaves extract on the corrosion of mild steel in $\mathrm{H}_{2} \mathrm{SO}_{4}$, J. W. African Sci. Assoc. 37 (1994) 13-30.

[13] G. Gece, The use of quantum chemical methods in corrosion inhibitor studies, Corros. Sci. 50 (2008) 2981-2992.

[14] E.E. Oguzie, S.G. Wang, Y. Li, and F.H. Wang, influence of iron microstructure on corrosion inhibitor performance in acidic media, J.phys. Chem. C, vol. 113, (2009) 8420-8429.

[15] E.E. Ebenso, U.J. Ibok, U.J. Ekpe, S. Umorem, E. Jackson, O.K. Abiola, N.C. Oforka and S. Martinez, Corrosion inhibition studies of some plant extracts on aluminium in acidic medium, Trans. SAEST 39 (4) 2004, 117-123.

[16] B. Mernari, H. El-Attari, M.Traisnel, F . Bentiss and M. Lagrenee, Inhibiting effects of 3,5-bis (n-pyridyl)-4-amino-1,2,4-triazoles on the corrosion for mild steel in $1 \mathrm{M} \mathrm{HCl}$ medium, Corrosion, 40 (1998) 391-399.

[17] M. Hosseini, S.F.I. Mertens, M.Ghorbani and M.R Arshadi, Asymmetrical Schiff bases as inhibitors for mild steel corrosion in sulphuric acid media, Mater. Chem. Phy. 78 (2003) 800-808.

[18] FBMS H, El Attari, A. ElBribri, and L.Mhaidra, Synthesis and anticorrosion for carbon steel of 4-amino-3,5 Bis (4-Hydroxy-3-methoxy)-1,2.4 Triazole in hydrochloric acid solution, American Journal of Engineering Research vol.4 iss.3 (2015) 44-51.

[19] A.O. James, N.C. Oforka and O.K. Abiola, Inhibition of corrosion of aluminium in hydrochloric acid by pyridoxal hydrochloric, Corros. Sci.Eng.7, Preprint 21 (2005)

[20] B.I. Ita and O.E. Offiong, Inhibition of steel corrosion in hydrochloric acid by pyridoxal-(4methylthiosemicar banzone) and its Zn (11) complex, Mater, Chem. Phys.48, (1997) 164-169.

[21] N. O. Eddy, Inhibitive and adsorption properties of ethanol extract of Colocasia esculenta leaves for the corrosion of mild steel in $\mathrm{H}_{2} \mathrm{SO}_{4}$, Int. J. Phys. Sci. 4 (2009) 1-7.

[22] E.E. Oguzie, C.B. Adindu, C.K.C Enenebaku, C.E. Ogukwe, A.M. Chidiebere and K.L. Oguzie, Natural products for material protection: mechanism of corrosion inhibition of mild steel by acid extracts of Piper guineense, The Journal of Phy. Chemistry C 116 (25), (2012)13603-13615.

[23] E.E. Oguzie, C.E. Ogukwe, J.N. Ogbulie, F.C. Nwanebu, C.B. Adindu, I.O. Udeze, K.L Oguzie and F.C. Eze, Broad spectrum corrosion inhibition: Corrosion and microbial (SRB) growth inhibiting effects of Piper guineense extract, Journal of Mat. Sci. 47 (2012) 3592-3601.

[24] N.S. Patel, S. Jauhariand, G.N. Mehta, S.S. Al-Deyab, I. Warad and B. Hammaouti, Mild steel corrosion inhibition by various plant extracts in $0.5 \mathrm{M}$ sulphuric acid, Int. Journ. of Elect. Sci. 8 (2013) 2635-2655.

[25] A. Popova, E. Sokolova, S. Raicheva and M. Christov, AC and DC study of the temperature effect on mild steel corrosion in acidic media in the presence of benzimidazole derivatives, Corros. Sci. 45 (2003) 33-58.

[26] E.E. Oguzie, S.G. Wang, Y. Li and F. H Wang, Influence of iron microstructure on corrosion inhibition performance in acidic media, J. Phy. Chem. 113, 19 (2009) 8420-8429.

[27] A. Y. El-Etre, Inhibition of acid corrosion of carbon steel using aqueous extract of olive leaves, J. Colloid Interface Sci. 314, 2 (2007) 578-83 
[28] M. Ozcan and I.Dehri, Electrochemical and quantum chemical studies of some sulphur containing organic compounds as inhibitors for the acid corrosion of mild steel, Progr. Org. Coat. 51 (2004) 181-187.

[29] M. Ozcan, I.Dehri and M. Erbil, Organic sulphur containing compounds as corrosion inhibitors for mild steel in acidic media: correlation between inhibition efficiency and chemical structure, Appl.Surf. Sci.236 (2004) 155-164.

[30] B.J. Delley, An all electron numerical method for solving the local density functional for polyatomic molecules, Chem. Phys. 92 (1990) page 508.

[31] B.J. Delley, from molecules to solid with the Dmol3 approach, Chem. Phys.113 (2000) page 7756.

[32] K. Funki, Theory of orientation and stereoselection, Springer-Verlag, New York, 1975.

[33] Z. Zhou and R.G. Parr, Activation hardness: New index for describing the orientation of electrophilic aromatic substitution, J. Am. Chem. Soc. 112 (1990) 5720-5724.

[34] L.M. Rodriguez-Valdez, A. Martinez-Villafane and D. Glooman-Mitinik, Computational simulation of the molecular structure and properties of heterocyclic organic compounds with possible corrosion inhibition properties, THEOCHEM 713 (1) (2005) 65-70.

[35] V.S. Sastri and J.R. Perumareddi, Molecular orbital theoretical studies of some organic corrosion inhibitors Corrosion, Corros. Sci., vol.53 no.8, (1997) 617-622.

[36] J.U. Hong, L.I Ding S.Can and J.J. Chen, Quantum chemical study on the corrosion inhibition of some Oxadiazoles, Advanced in Mat. Sci. and vol.(2015) 20155 pages

[37] J. Bartley, N. Huynh, S.E. Bottle, H. Flitt, T. Notoya, and D.P. Schweinsberg, Computer simulation of the corrosion inhibition of copper in acidic solution by alkyl esters of 5carboxybenzotriazole, Corros. Sci., 45, 81 (2003) 81-96. 